\title{
Sentido e alcance do processo eleitoral no regime democrático
}

\author{
FÁBIO KONDER COMPARATO
}

\begin{abstract}
A ESSÊNCIA DA democracia, como a própria etimologia indica, é a titularidade e o exercício do poder político supremo - o kyrion da filosofia aristotélica - pelo povo, isto é, o conjunto dos cidadãos. Teoricamente, pode-se discutir a abrangência do conceito de povo entre o alcance máximo de todos os que vivem no território do Estado, capazes de declarar sua vontade livremente, e o limite mínimo de um grupo reduzido de pessoas; vale dizer, entre a poliarquia e a oligarquia. A História apresenta-nos uma gama extensa de variações, nesse particular. Mas o que não se pode é confundir a democracia com os regimes que claramente dispensam a manifestação da vontade popular, ou falseiam, por meio de engenhosos mecanismos, a sua expressão legítima.
\end{abstract}

Importa também distinguir o poder do povo, do poder sobre o povo, e a diferente função do processo eleitoral em um e outro caso (1). No regime democrático, o povo exerce sua soberania, ou diretamente, ou mediante representantes. Estes últimos não devem ser confundidos com o governo, isto é, com aqueles que dispõem de poder sobre o povo (2). Quando o povo elege um chefe de Poder Executivo, numa democracia, este não se transforma, pelo fato eleitoral, em representante do povo. A sua eleição ou escolha equivale a uma manifestação de consentimento popular ao exercício do governo, que passa a ser fiscalizado pelo povo, diretamente, ou por seus representantes, que são, em geral, os membros do Parlamento.

Numa democracia, já observara Montesquieu, o povo é, sob certos aspectos, monarca e, sob outros, súdito. Ele é monarca pelos seus sufrágios, que exprimem sua vontade. Daí porque as leis que regulam o modo de proceder das eleições são tão fundamentais no regime democrático, quanto a lei de sucessão dinástica numa monarquia (3).

Ora, exatamente em função do vínculo indissolúvel entre democracia e escolha ou consentimento popular, bem como em razão do prestígio crescente que esse regime político passou a ter em todo o mundo na segunda metade do século XX, as diferentes autocracias ou oligarquias, que não podiam correr o risco de perder sua aparência de legitimidade, procuraram manter oficialmente o processo eleitoral, preservando no entanto o seu fun- 
cionamento de todo risco capaz de afetar o poder supremo da minoria governante.

A manipulação eleitoral, a bem dizer, não é um fato novo em nossa história política. Com maior ou menor dose de refinamento, ela sempre ocorreu entre nós. Uma rememoração, ainda que sumária, do nosso passado eleitoral nem confirmar amplamente esse fato.

\section{Sumário da variação sofrida pelo processo eleitoral, na história do Brasil independente}

A Constituição de 1824, como sabido, determinou que as eleições de deputados e senadores, para a composição da Assembléia Geral, se fizessem por sufrágio indireto e censitário (arts. 90 e ss.).

Em 1842, diante do escândalo geral provocado pelo ambiente de violência em que se desenrolara o último pleito, conhecido em nossa história política como "as eleições do cacete", o Governo decidiu baixar um decreto regulador do processo eleitoral, o de $\mathrm{n}^{\circ} 157$, de 4 de maio. Em que pese às boas intenções governamentais, o Decreto era evidentemente inconstitucional, e a oposição não deixou de denunciar o fato. $\mathrm{O}$ art. 97 da Carta estatuia que "uma Lei regulamentar marcará o modo prático das Eleições, e o número dos Deputados relativamente à população do Império". Um decreto governamental não podia, a todas as luzes, ser aceito como o equivalente de uma lei.

A regulação legal exigida pela Constituição acabou sendo votada em 19 de agosto de 1846, sem que, no entanto, a sua constitucionalidade estivesse isenta de impugnações. O diploma legal mandava computar em prata o censo eleitoral que a Carta havia estabelecido em moeda nacional. Além disso, a nova lei excluiu o direito de voto dos magistrados e altos funcionários. Tais disposições, como foi oportunamente assinalado, dificilmente poderiam ser entendidas como a regulação do "modo prático das eleições".

Em 1855, outro Decreto governamental, o de $\mathrm{n}^{\circ} 842$, cuja inconstitucionalidade era ainda mais pronunciada, instituiu entre nós a eleição por distritos, então chamados círculos, como em Portugal. O mais curioso é que essa eleição distrital majoritária, geralmente considerada pelos especialistas de hoje como uma brutalidade contra a minoria, foi defendida ardorosamente pelo seu idealizador - Honório Hermeto Carneiro Leão, marquês de Paraná - como o modo mais eficaz de se evitarem as chamadas "câmaras unânimes". Escusa lembrar que o apregoado remédio não curou a moléstia, que continuou a grassar durante todo o Império e a $1^{\text {a }}$ República. 


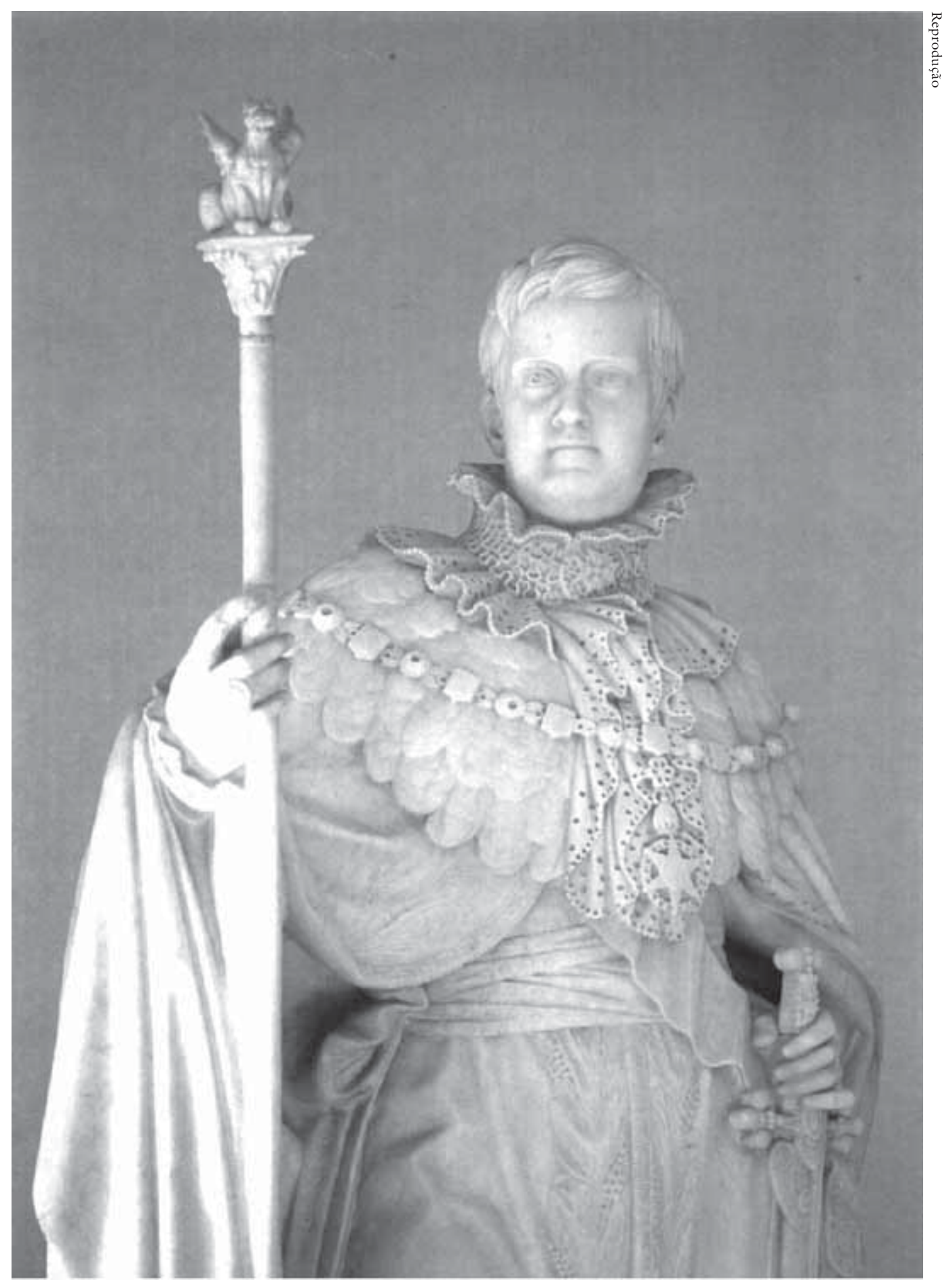

Escultura do imperador Dom Pedro II 
Cinco anos depois, o Decreto $\mathrm{n}^{0} 1.082$ alargou a representação dos círculos para três deputados, votando o eleitor em chapas fechadas de três candidatos. Mas enquanto pelo sistema de 1855 exigia-se para a eleição a maioria absoluta dos votos, instituindo-se para tanto dois turnos de votação, em 1860 o novo regulamento eleitoral contentou-se com a maioria relativa.

Como ainda persistisse a ocorrência das câmaras unânimes, o Governo resolveu baixar o Decreto $\mathrm{n}^{\mathrm{o}} 2.675$, de 20 de outubro de 1875 , com o propósito de forçar a representação da minoria. Doravante o voto seria dado em apenas dois candidatos, embora continuassem os distritos a ser representados por três deputados. Era a lei do terço.

Não obstante essa contínua alteração das regras eleitorais, a minoria timbrava em não aparecer no Parlamento. Era geral o sentimento de que se haviam esgotado todas as possibilidades oferecidas pelo sistema representativo estatuído pela Carta Constitucional. Em discurso proferido na Câmara por ocasião das discussões da lei do terço, José de Alencar vocalizou de certa forma a opinião dominante, ao concluir: "Temos experimentado os círculos, os triângulos, diversas formas de manipulação, falta a eleição direta. É o travesseiro para o enfermo que não tem repouso" (4).

A oferta desse travesseiro repousante enfrentava, porém, um grave obstáculo constitucional: a necessidade de se reformar a Carta era, agora, inafastável e insofismável. Ora, a reforma constitucional fazia-se, então, por um processo sem dúvida mais democrático do que o que passou a vigorar com a república, mas, por isso mesmo, muito demorado. Inicialmente, deliberava-se sobre proposta, cuja iniciativa pertencia a pelo menos um terço dos deputados, da necessidade de se emendar tal e qual artigo da Constituição. Vencida a necessidade da reforma, expedia-se uma lei, pela qual determinava-se aos eleitores dos deputados à seguinte legislatura, "que nas procurações lhes confiram especial faculdade para a pretendida alteração, ou reforma", a qual seria, só então, proposta, discutida e votada (arts. 175 e ss.).

O governo imperial tinha, porém, pressa em introduzir a eleição direta e o Imperador receio de que uma discussão de mudança constitucional degenerasse em desordem política. Deliberou-se, então, reformar a Carta mediante lei ordinária, sem maiores exigências. Era uma indisfarçável violência, que os legisladores faziam à Constituição. A Câmara dos Deputados transformava-se dessa forma, como bem qualificou José Bonifácio, o Moço, em uma "constituinte constituída". Infelizmente, como se sabe, não foi este o único caso em que se praticou semelhante abuso em nossa agitada história constitucional. 
O Gabinete Sinimbú, que apresentara a proposta por meio de seus correligionários políticos, não logrou contudo vê-la aprovada. Foi preciso aguardar a constituição do Gabinete Saraiva e a promulgação da lei de 1881, para que tivéssemos, enfim, um sistema de eleições diretas, voltando-se, para esse efeito, à organização do eleitorado em círculos, agora chamados definitivamente distritos, de um só deputado.

Proclamada a República, a nova Constituição, ecoando a velha queixa contra as "câmaras unânimes" do Império, determinou que na Câmara dos Deputados se garantisse "a representação da minoria" (art. 28, in fine). Para obedecer ao preceito, a primeira lei eleitoral republicana, a de $\mathrm{n}^{\circ} 35$, de 26 de janeiro de 1892, à míngua de idéias novas, voltou à fórmula dos círculos de três deputados, votando o eleitor em apenas dois.

Enquanto isso, cada estado federado organizava autonomamente o seu direito eleitoral. O Rio Grande do Sul, sob a liderança de Júlio de Castilhos, adotou desde logo os preceitos do positivismo puro e duro, impondo em sua lei de 1897 o voto a descoberto. A Exposição de Motivos justificou a medida, afirmando que era preciso "viver às claras", e que o voto secreto constituia um dos mais poderosos estímulos à corrupção eleitoral. O legislador federal acabou cedendo à influência dessas idéias. A Lei Rosa e Silva, de 1904, deu ao eleitor a faculdade de votar a descoberto.

Este é mais um episódio que ilustra a nossa propensão a adotar, em matéria eleitoral, com a mais firme convicção, remédios absolutamente contraditórios para os mesmos males. A Lei de 1855, como forma de proteção à minoria, introduziu a eleição distrital majoritária, que sempre foi tida como o modo mais drástico de se esmagarem os minoritários. Meio século depois, com o fito de lutar contra a corrupção do voto, a lei eleitoral gaúcha de 1897 e a Lei Rosa e Silva procuraram impedir o voto secreto, que viria a ser, como todos sabem, o cavalo de batalha dos revolucionários de 1930 contra as práticas eleitorais da República Velha.

A nossa primeira Constituição republicana inaugurou, ademais, o sistema de correções quantitativas à representação popular, determinando que o número de deputados federais não seria nunca inferior a quatro por estado.

Foi só depois da Revolução de 30, com o Código Eleitoral de 1932 e a Constituição de 1934, que introduzimos o sistema da representação proporcional, preconizado por José de Alencar em livro escrito em 1866 e publicado em 1868 (5). A fórmula idealizada por Assis Brasil - listas partidárias abertas e voto nominal (6) - viria a ser o principal fator de enfraquecimento dos partidos políticos. O objetivo visado pelo idealizador do siste- 
ma, aliás, não era outro: Assis Brasil não fez mistérios quanto ao seu propósito de acabar com a prática do partido único, existente na República Velha.

Importante criação do Código de 1932 foi, sem dúvida, a Justiça Eleitoral. Tanto mais que, na reforma da Constituição, votada em 1926, incluirase um dispositivo de claro sabor autocrático: "Nenhum recurso judiciário é permitido, para a justiça federal ou local, contra ... a verificação dos poderes, o reconhecimento, a posse, a legitimidade e a perda de mandato dos membros do Poder Legislativo ou Executivo, federal ou estadual".

Após o interregno do Estado Novo getulista, a Constituição de 1946 voltou ao sistema do Código Eleitoral de 1932, sem a representação classista introduzida pela Constitição de 1934. Registre-se, no entanto, que em 7 de janeiro de 1946, antes portanto de promulgada a nova Constituição, o Decreto $n^{\circ} 8.566$ determinou que a votação para a Câmara dos Deputados se fizesse pelo sistema de listas partidárias fechadas. Mas a fórmula, que corresponde à única representação proporcional legítima, contrariava o tradicional personalismo de nossos políticos. O Decreto entrou em vigor, mas não foi aplicado.

No tocante à composição das Câmara de Deputados, a Constituição (art. 58) suprimiu o número mínimo de representantes por estado, mantendo apenas um redutor no número de deputados a partir de determinado nível populacional, sistema esse que já existia desde a Constituição de 1891.

Sobre o triste período do regime militar, nada há a dizer, pois as eleições, quando as havia, não passavam de mera encenação para o público exterior. É curioso, porém, que na fase da abertura lenta, gradual e segura, uma mal denominada emenda constitucional, de $\mathrm{n}^{\mathrm{o}} 22$, promulgada em $5 \mathrm{de} \mathrm{ju}$ lho de 1982, determinou, para gáudio de certos cientistas políticos, que "na forma que a lei estabelecer, os deputados federais e estaduais serão eleitos pelo sistema distrital misto, majoritário e proporcional". A lei, bem entendido, não estabeleceu coisa alguma. Tivemos mais uma reforma eleitoral no papel.

E com isto chegamos ao regime pós-militar, para o qual Afonso Arinos de Mello Franco cunhou a denominação otimista "República Nova". A novidade, como todos sabem, ficou só na alcunha.

Quase um século após a proclamação da República, a emenda constitucional $\mathrm{n}^{\mathrm{o}} 25$, de 15 de maio de 1985, reatribuiu aos analfabetos a capacidade política, que a Constituição de 1891, reafirmando a Lei Saraiva, lhes havia retirado. Doravante, os que não chegaram a adquirir as primeiras letras, pelo descaso dos Poderes Públicos, já não seriam penalizados por uma deficiência da qual não podiam, honestamente, ser responsabilizados (7). 
A mesma emenda ${ }^{\circ} 25$ fixou em 8 e 60 o número mínimo e máximo, respectivamente, de deputados federais por estado.

A Constituição de 1988, praticamente, nada inovou em matéria eleitoral, salvo no que diz respeito ao número máximo de deputados federais por Estado. Em rídicula concessão à magnitude do maior eleitorado estadual, fixou o teto de repreesentantes em $70 \mathrm{em}$ cada circunscrição (art. $45, \mathfrak{S}$ $1^{\circ}$ ), quando o mínimo justo seria de pelo menos 120 .

A grande inovação viria com a emenda constitucional $n^{0} 16$, de 4 de junho de 1997, a qual, contra toda a tradição, a prudência e o bom-senso, introduziu a possibilidade de reeleição dos chefes de Poder Executivo. É uma iniciativa temerária, que virá certamente reforçar ainda mais o poder irresponsável de nossos governantes, sobretudo depois que a interpretação espúria, vingou sustentada pelo Planalto, de que os candidatos à reeleição não precisam se desincompatibilizar.

No plano da legislação eleitoral, o espírito pouco democrático do regime pós-militar também se fez sentir. A partir de 1985, tivemos quase que uma lei especial para cada eleição. Os políticos da maioria dominante procuravam adaptar a legislação às suas conveniências pessoais, praticando aquele abuso de poder que Rousseau considerava o mais corruptor de todos: a manipulação legislativa. A recente Lei n ${ }^{0} 9.504$, de 30 de setembro de 1997, parece ter posto fim a essa sucessão de leis eleitorais de encomenda. Ela se ressente, porém, a meu juízo, de um grave defeito de origem: regulando matéria fixada na própria Constituição, e que diz respeito a um dos mais importantes atributos da cidadania, ela deveria ter sido votada como lei complementar, e não como lei ordinária.

\section{O povo ausente ou privado de voz}

Como se acaba de ver, ensaiamos neste país, desde a independência, os mais variados sistemas eleitorais, com extensa gama de espécies e subespécies. O resultado, porém, sempre foi o mesmo: os grupos dominantes jamais perdem o poder. Em nenhum outro setor da vida nacional terá, talvez, mais perfeita aplicação o ditado francês: plus ça change, plus c'est la même chose.

A razão de ser dessa perpétua alteração imobilista não é difícil de discernir.

Até 1945, o povo foi mero figurante e não personagem na cena política. Ele compunha o eleitorado virtual, como diríamos hoje na linguagem eletrônica. 
Por ocasião do último pleito realizado durante o regime imperial, em 1886 - as primeiras eleições diretas que conheceu o país -, os que compareceram às urnas representavam menos de $1 \%$ da população nacional. Durante toda a República Velha, a média dos votantes, em todos os pleitos, foi de $2,6 \%$ da população.

A partir de 1945, o figurante torna-se realmente personagem, com um papel próprio a desempenhar. Mas nesse desempenho próprio, ele raramente se aparta do roteiro que o diretor da peça teatral lhe atribui de ofício.

A bem dizer, não há nisso nada de surpreendente. Em vão procura-se o povo, nos principais fastos de nossa história. Ele teima em permanecer ausente, ou, quando aparece, é para se mostrar como que privado de palavra. É assim mesmo, aliás, que Vieira o descreve, no sermão da visitação de Nossa Senhora, pregado por ocasião da chegada à Bahia do marquês de Montalvão, vice-rei do Brasil, em junho de 1640 (8). "Ut facta est vox salutationis tuae in auribus meis, exultavit in gaudio infans. Comecemos por esta última palavra", propôs o grande pregador. "Bem sabem os que sabem a língua latina, que esta palavra, infans, infante, quer dizer o que não fala. Neste estado estava o menino Batista, quando a Senhora o visitou, e neste esteve o Brasil muitos anos, que foi, a meu ver, a maior ocasião de seus males. Como o doente não pode falar, toda a outra conjectura dificulta muito a medicina. (...) O pior acidente que teve o Brasil em sua enfermidade foi o tolher-se-lhe a fala: muitas vezes se quis queixar justamente, muitas vezes quis pedir o remédio de seus males, mas sempre lhe afogou as palavras na garganta, ou o respeito, ou a violência; e se alguma vez chegou algum gemido aos ouvidos de quem o devera remediar, chegaram também as vozes do poder, e venceram os clamores da razão".

É óbvio que o Brasil, a que se refere Vieira, não é o conjunto dos poderosos da época, que diziam à metrópole exatamente o que esta queria ouvir. É o povo sem poder e sem voz.

Às vésperas da Independência, Hipólito da Costa declarava em Londres, no Correio Braziliense: "Ninguém deseja mais do que nós, as reformas úteis, mas a ninguém aborrece mais do que nós que essas reformas sejam feitas pelo povo". Um governador mineiro repetiu declaração análoga um século depois, às vésperas da Revolução de 1930.

Ora, a partir de 1945, o grande ausente irrompe na cena política, convocado para votar na eleição dos governantes. Todas as precauções, porém, são tomadas para que ele fale o mínimo possível, e fale apenas sobre matéria que não escolheu e na ocasião que lhe é ditada. Quando as circuns- 
tâncias indicam que há riscos sérios de o roteiro não ser fielmente seguido, simplesmente fecha-se o teatro e adia-se a representação. "A política brasileira", observou com lucidez Hermes Lima, "tem a perturbá-la, intimamente, secretamente, desde os dias longínquos da Independência, o sentimento de que o povo é uma espécie de vulcão adormecido. Todo perigo está em despertá-lo. Nossa política nunca aprendeu a pensar normalmente no povo, a aceitar a expressão da vontade popular como base da vida representativa" (9).

O magno problema político brasileiro não é, pois, como pareceu a certos cientistas políticos sempre prontos a assimilar teses e categorias forjadas nas oficinas intelectuais do primeiro mundo, uma crise de governabilidade (10). O nosso problema é mais profundo e diz respeito, muito além da esfera de governo, ao próprio regime político: é a tentativa absurda de fazer funcionar uma democracia sem povo.

A partir de 1945, quando o número de votantes nas eleições nacionais cresceu progressivamente, de $16 \%$ da população a mais de $50 \%$ nos anos 80 em diante, o grande desafio para os grupos ou classes dominantes consistiu, justamente, em admitir o funcionamento do mecanismo eleitoral sem que a maioria do povo assumisse, em razão de sua esmagadora predominância numérica, as rédeas do Estado.

Num primeiro momento, recorreu-se ao expediente do populismo, que é a quintessência da demagogia. Nas eleições majoritárias, os donos do poder escolhiam candidatos que gozavam de grande favor popular, mas que se comprometiam, expressa ou tacitamente, a fazer o jogo das classes dominantes. O esquema revelou-se altamente perigoso e acabou produzindo efeitos desastrosos, com Janio Quadros e Fernando Collor de Melo. No primeiro caso, aliás, as classes dominantes, apavoradas, pediram socorro às Forças Armadas, instalando uma militocracia que durou duas décadas. No segundo, já estava em funcionamento um outro esquema de poder, altamente sofisticado, que assegurou, sem maiores traumatismos, a permanência do regime oligárquico: foi a manipulação competente da opinião pública pelos meios de comunicação de massa.

Entramos, assim, na última fase da evolução da oligarquia brasileira. O conjunto dos meios de comunicação de massa, notadamente o rádio e a televisão, tornaram-se o maior e mais novo poder informal de nossa organização política. Estamos, de fato, diante de um poder autêntico e não de uma força política inorgânica. Por trás do véu da concorrência comercial, as empresas de comunicação criaram uma unidade interna, estruturada juridicamente, e uma estratégia de atuação em comum com os detentores do 
poder oficial, perante o povo. Hoje, como todos sabem, ainda que os meios de comunicação de massa sejam impotentes para fazer um presidente da República, eles têm capacidade suficiente para impedir que um candidato adversário das forças dominantes conquiste a presidência pela via eleitoral. A organização contemporânea da imprensa, do rádio e da televisão representa, em nosso país, o mais sugestivo exemplo daquele poder impediente de que falava Montesquieu (11).

O mecanismo das eleições, viciado assim em sua essência, falseia completamente o funcionamento do regime.

Quando essa doença toma conta do corpo político, pode conduzi-lo, na falta de uma intervenção oportuna e adequada, a um avançado estado de decomposição. É preciso, pois, voltar urgentemente à consideração dos princípios fundamentais da democracia. É preciso voltar a Rousseau e a seu radicalismo popular.

Para o grande genebrino, defendendo o modelo contra o qual se forjou, contemporaneamente, a política de privatizações e de liquidação do Estado Social, quanto mais um Estado é bem organizado, mais os cidadãos se ocupam de questões ligadas ao bem comum e menos de questões de interesse particular. Sucede mesmo, nesse Estado bem organizado, que as questões privadas tornam-se menos numerosas, uma vez que a realização do bem comum aumenta o grau de felicidade individual, reduzindo com isso a necessidade de cada qual recorrer aos cuidados particulares (12).

É por isso que ele via na representação popular a negação da soberania do povo. Os mandatários tornam-se, fatalmente, prevaricadores e passam a atuar contra o interesse do mandante. Os eleitos confiscam o Estado e substituem-se ao povo. "A Soberania não pode ser representada", sustentava Rousseau, "pela mesma razão que ela não pode ser alienada; ela consiste essencialmente na vontade geral, e a vontade geral não se representa; ela é a mesma, ou é outra; não há meio termo. Os deputados do povo não são pois, nem podem ser, seus representantes; eles são apenas seus comissários; eles nada podem concluir definitivamente. Toda lei que o povo não ratificou pessoalmente é nula; não é uma lei” (13).

Ao relembrar esses ensinamentos de um democrata radical, não estou propondo instaurar, numa sociedade de 160 milhões de pessoas, um sistema de democracia direta exclusiva. O próprio Rousseau, aliás, tendo sem dúvida a cidade independente de Genebra diante dos olhos, entendia que somente nos pequenos Estados seria possível instituir um regime de autêntica soberania popular (14). Antes dele, Montesquieu já sustentara que o 
regime republicano só pode prosperar nos pequenos Estados, onde o bem comum está mais perto de cada cidadão e os abusos são menores e menos protegidos (15).

Mas é inegável que a democracia hodierna, qualquer que seja o tamanho da sociedade política, exige a instituição de um sistema de decisões populares diretas, que resolvam as questões coletivas fundamentais e estabeleçam diretrizes vinculantes para os órgãos de governo. É o governo submetendo-se ao soberano, o governo delegado do povo, e não dono do poder, a representar para o povo como um ator teatral representa para a platéia. E, justamente porque o aparelho governamental é cada vez mais forte nos grandes Estados, torna-se indispensável, como insistia Rousseau, que o povo soberano se pronuncie mais freqüentemente (16). É a policy determination, dirigindo a policy execution, para usarmos das categorias propostas por Karl Loewenstein (17). Somente pela Lei $\mathrm{n}^{0} 9.709$, de 18 de novembro de 1998, isto é, 10 anos depois de promulgada a Constituição, é que o Congresso Nacional regulou o referendo, o plebiscito e a iniciativa popular legislativa. E, ainda assim, tomando o cuidado de esvaziar de todo conteúdo prático essas prerrogativas fundamentais de soberania popular (18).

Antes de mais nada, a competência decisória original do povo é inalienável, como atributo da soberania, em matéria constitucional. Hoje, já não se podem aceitar como legítimas as Constituições que não tenham sido referendadas pelo povo soberano, nem elaboradas por uma assembléia superior aos órgãos normais de funcionamento do Estado convocada exclusivamente para essa tarefa. Da mesma forma, nenhuma alteração do texto constitucional em vigor pode deixar de ser submetida ao referendo popular.

Por isso mesmo, se tivermos de reformar o sistema eleitoral deste país, para corrigir os defeitos gravíssimos acima apontados, a mais elementar exigência de autenticidade democrática impõe que tal reforma, em suas linhas gerais, seja feita por decisão do próprio povo, e nunca por obra de seus representantes. Tanto mais que a votação, pelos representantes do povo, das normas que regem o processo pelo qual eles próprios foram eleitos, constitui inadmissível violação do princípio que proibe a prática, por um representante, de atos que digam respeito aos seus próprios interesses, em conflito com os interesses do representado. A representação popular, em suma, só é legítima quando instituída pelo próprio povo.

Por outro lado, ainda no campo institucional, a instauração da democracia autêntica, entre nós, exige que se submeta aos princípios democráticos o formidável poder não-institucionalizado dos meios de comunicação 
de massa. Os órgãos de comunicação não são empresas quaisquer, que produzem bens ou prestam serviços ao consumidor. Elas não se situam no setor econômico, mas no campo político. E isto, pelo fato de interferirem decisivamente na formação da opinião pública, sendo certo que algumas delas só podem atuar mediante a utilização de um bem público, isto é, bem do povo, que é o espaço no qual são emitidas as ondas hertzianas. É intolerável, numa democracia digna desse nome, que esses poderosos instrumentos de ação política sejam oligopolizados em mãos das classes dominantes.

Tudo isso, no campo puramente institucional. Mas a democracia, como todo regime político, não se reduz a um conjunto de instituições jurídicas. Ela vive também em função de uma ética própria, centrada em torno de valores fundamentais. Ela se alimenta, ademais, de uma prática ou estilo de vida. A prática democrática é formada pelos costumes do povo. Ora, os costumes sociais, como enfatizou Montesquieu, não se constituem nem se reformam por lei. Eles nascem e se aperfeiçoam por obra da educação. Não há mais segura defesa das instituições constitucionais de uma democracia do que a formação, no seio do povo, de um vigoroso ethos democrático, representado pelas virtudes cardeais da cidadania ativa: a participação popular permanente nos assuntos de governo e o respeito escrupuloso dos direitos humanos.

\section{Notas}

1 Esta distinção foi claramente exposta por Karl Loewenstein, em sua obra Political power and the governmental process, reeditada ampliadamente em alemão sob o título Verfassungslehre, $3^{\text {a }}$ ed., Tübingen, J C B. Mohr, 1975, p. 34 e ss.

2 Em sentido exatamente contrário, o idealismo alemão apresenta o governo como representante do Estado como um todo perante o indivíduo. Cf. Carl Schimitt, Verfassungslehre. $7^{\text {a }}$ ed., Berlim, Duncker \& Humblot, 1989, p. 212; Gerhard Leibholz, Das Wesen der Repräsentation und der Gestaltwandel der Demokratie im 20. Jahrbundert, $3^{\text {a }}$ ed., Berlim, Duncker \& Humblot, 1966, p. 79 e ss.

3 "Le peuple, dans la démocratie, est, à certains égards, le monarque; à certains autres, il est le sujet. Il ne peut être monarque que par ses suffrages qui sont ses volontés. La volonté du souverain est le souverain lui-même. Les lois qui établissent le droit de suffrage sont donc fondamentales dans ce gouvernement. En effet, il est aussi important d'y régler comment, par qui, à qui, sur quoi, les suffrages doivent être donnés, qu'il l'est dans une monarchie de savoir quel est le monarque, et de quelle manière il doit gouverner". De l'Esprit des Lois, livro II, cap. 2. 
4 Citado por Walter Costa Porto, O Voto no Brasil: da Colônia à $5^{a}$ República, História Eleitoral do Brasil, v. I, p. 85.

5 Systema Representativo. O Senado Federal publicou uma edição fac-similar do livro em 1997.

6 O livro capital de Assis Brasil, Democracia representativa: do voto e do modo de votar, foi publicado em 1893.

7 Durante o debate na Câmara sobre o projeto Sinimbú de eleição direta, o qual suprimia o direito de voto dos analfabetos, o Ministro Leôncio de Carvalho afirmou candidamente: "Até a execução da reforma (eleitoral) há muito tempo para os analfabetos procurarem escola". Estava-se, então, no ano da graça de 1879. Mais de 120 anos depois, seria arriscado afirmar que a mentalidade dos governantes no país tenha sofrido alguma mudança.

8 Sermões, v. IX, Porto, Lello \& Irmão, Editores, 1951, p. 334.

9 Cit. por Raymundo Faoro, Os donos do poder, I, $2^{\text {a }}$ ed., Porto Alegre, p. 323.

10 Em A retórica da intransigência: perversidade, futilidade, ameaça. São Paulo, Companhia das Letras, 1995, p. 100 e ss.; Albert O. Hirschman mostrou que a tese da crise de governabilidade tem origem num relatório da Comissão Trilateral de 1975, publicado sob o título The crisis of democracy, em que se sustentou que o excesso de gastos governamentais, notadamente com programas de política social, poria em risco a própria democracia. Foi a verdadeira declaração de guerra do neoliberalismo contra o Estado do Bem-Estar Social.

11 "J'appelle faculté de statuer, le droit d'ordonner par soi-même, ou de corriger ce qui a été ordonné par un autre. J'appelle faculté d'empêcher, le droit de rendre nulle une résolution prise par quelque autre; ce qui étoit la puissance des tribuns de Rome". De l'Esprit des Lois, livro XI , cap. VI.

12 “Mieux l'État est constitué, plus les affaires publiques l'emportent sur les privées dans l'esprit des citoyens. Il y a même beaucoup moins d'affaires privées, parce que la somme du bonheur commun fournissant une portion plus considérable à celui de chaque individu, il lui en reste moins à chercher dans les soins particuliers". Du Contrat Social, livro $3^{\circ}$, cap. XV.

13 Op. cit., ibid.

14 "Je réponds que c'est toujours un mal d'unir plusieurs villes en une seule cité, et que, voulant faire cette union, l'on ne doit pas se flatter d'en éviter les inconvéniens naturels. Il ne faut point objeter l'abus des grands États à celui qui n'en veut que de petits". Op.cit., livro $3^{\circ}$, cap. XIII.

15 Op. cit., livro VIII, cap. XVI. 
16 "Quant aux retours plus ou moins fréquens des assemblées légitimes (assembléias de todo o povo), ils dépendent de tant de considérations qu'on ne sauroit donner là-dessus de règles précises. Seulement on peut dire en général que plus le Gouvernement a de force, plus le Souverain doit se montrer fréquemment”. Id., ibid.

17 Op. cit., p. 40.

18 Sobre o assunto, a melhor monografia continua sendo a de Maria Victoria de Mesquita Benevides, A cidadania ativa: referendo, plebiscito e iniciativa popular. São Paulo, Ática, 1991.

Fábio Konder Comparato, doutor em Direito pela Universidade de Paris, é professor titular da Faculdade de Direito da Universidade de São Paulo. 